Chinnadurai Prabhu

Murugesan Jayaraman

Mani Rajnikanth

https://doi.org/10.21278/TOF.43308

ISSN 1333-1124

eISSN 1849-1391

\title{
EXPERIMENTAL INVESTIGATION INTO FATIGUE BEHAVIOUR OF EN- 8 STEEL (080M40/AISI 1040) SUBJECTED TO HEAT TREATMENT AND SHOT PEENING PROCESSES
}

\begin{abstract}
Summary
EN-8 steel (also known as 080M40 or AISI 1040 steel) has been widely used in the fields of power transmission shafts, gears and automobile crankshafts due to its unique metal properties and versatility. Parts of these products may fail during cyclic loading which may result in production losses and delays. The objective of the study is to investigate the fatigue behaviour of EN-8 steel concerning its mechanical properties, such as tensile strength, yield stress, elongation and hardness, when it is subjected to heat treatment and shot peening processes. The fatigue test was conducted on samples that were not treated by any process (without treatment - WT), samples subjected to quenching and tempering (Q\&T), shot peened samples (SP), and samples subjected to a combination of quenching and tempering and the shot peening process (Q\&T and SP). One way ANOVA was performed on the average number of cycles of different treatments to validate the fatigue strength.
\end{abstract}

Key words: $\quad$ fatigue life, shot peening, quenching, tempering, EN-8 (080M40/AISI 1040) steel

\section{Introduction}

Rotating parts, which find their application in automotive and machine components, have a higher fatigue failure tendency than other elements. The phenomenon of fatigue failure mainly depends on the fatigue strength of the metal used for manufacturing such components. Hence, fatigue strength enhancement becomes essential and is of utmost importance to extend the life of components.

Figures 1 and 2 show the crack initiation and propagation and fatigue failure leading to the crankshaft fracture respectively.

Generally, the processes used to enhance the fatigue strength of EN 8 steel are heat treatment and shot peening.

Shot peening is the process of impacting a metal surface with hardened shot to produce a compressive residual stress layer which helps in reducing crack propagation. This is the major advantage of the shot peening process. Pandey [1] studied the effect of shot peening on the fatigue life of engineering components. All shot peening and material parameters are 
recommended to be taken into consideration as they affect the service life of engineering components and materials which are subjected to cyclic loading and aggressive environment. It was observed that in the case of hard materials, plastic deformation induced by the shot peening process hardens the top surface creating a soft layer below the surface and in the case when soft materials homogeneous deformation occurs enhancing hardness and avoiding crack nucleation. This study reveals that fatigue life and fatigue crack propagation life increase due to shot peening.

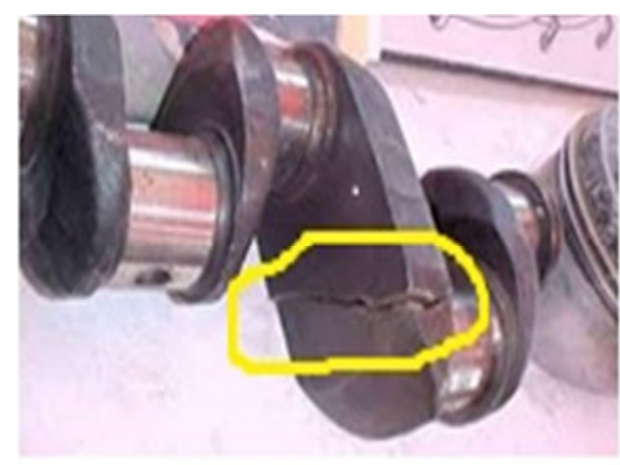

Fig. 1 Crack initiation and propagation
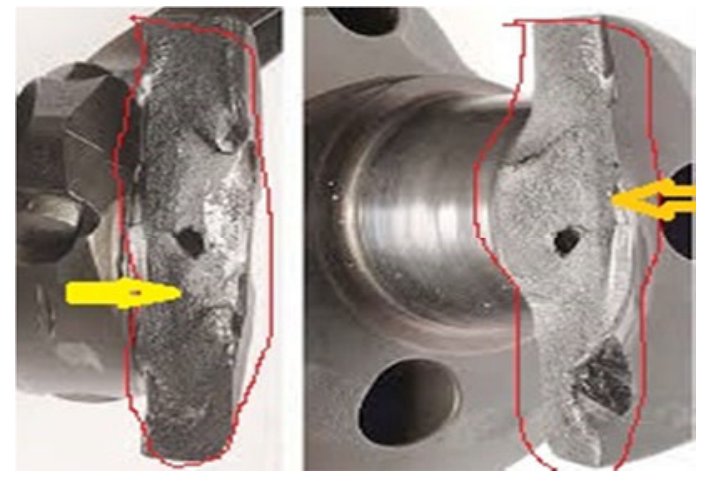

Fig. 2 Fatigue failure leading to the crankshaft fracture in crankshaft

The effect of quenching and tempering and the shot peening process on the fatigue strength of 51CrV4 steel was studied by Kubit [2]. A comparative study was carried out comparing the results of the treated specimens with the results of the untreated specimens. An important observation is that, after completion of both the Q\&T and the SP process, fatigue life increased by $86.3 \%$. Haradaa [3] studied the impact of micro shot peening process on the fatigue strength of spring steel JIS-SUP9 by conducting out-of-plane bending fatigue tests at a predetermined frequency of 200 cycles per minute and cycles of $10^{7}$ as the limiting number to evaluate fatigue properties. Overall results prove that hardness increases, and the surface defect is reduced when peening time is increased and that this is an efficient process for improving fatigue life of spring steel at high number of cycles.

Vielma [4] investigated various Almen intensities of shot peening and their effect on the fatigue life enhancement of structural steels. The result shows that the high intensity shot peening treatment is not preferable for the enhancement of the fatigue life of the selected metal as it increases surface hardening thereby increasing surface damage. Tekeli [5] compared SAE9245 steel specimens which were only heat treated with SAE9245 steel specimens that underwent only the shot peening process. The shot peening process improved the fatigue life of the SAE9245 steel by $30 \%$ as it creates residual compressive stress due to deformation hardening on the surface.

Heat treatment, e.g. quenching, tempering, annealing, carburizing, nitriding, etc., is a well-known conventional method to improve mechanical properties of metals. it is also a the method for amalgamating of the time regulated heating and cooling of specimens to yield better mechanical and physical properties without destruction of the shape of a metal specimen. Tanwer [6] investigated effects of various heat treatment processes, such as annealing and normalizing of mild steel and stainless steel. Korade [7] conducted a review of different heat treatment processes carried out on various tool steels testing the endurance limit. And he concluded that the cryogenic treatment yields better fatigue strength than other heat treatment processes.

Quenching is one of the heat treatment processes in which metal is heated above its recrystallization temperature and exposed to sudden cooling with water or oil. It is usually followed by tempering which involves heating the metal below its re-crystallization 
temperature. Quenching is mainly preferred for the treatment of steel to extend its life. Somer [8] studied the fatigue behaviour of (A193-51T-B7) alloy steel when subjected to two heat treatment processes, viz., annealing and quenching. It is found that quenching followed by tempering results in a decrease in the crack growth rate, whereas annealing increases the crack growth rate. Schino [9] studied the impact of quenching and tempering on steel with chromium and molybdenum as additives and found that this addition improved mechanical properties of steel. Rawdon [10] studied changes in the structure of martensitic carbon steel found after quenching followed by tempering. Senthilkumar [11] noticed that changing heat treatment parameters brings about changes in mechanical properties, which results in improved fatigue life and surface hardness. The author reviewed different surface heat treatments, such as quenching, tempering, carburizing etc., and concluded from the results that the tempered steel sample exhibits higher tensile strength than the untreated sample.

EN-8 steel is an accepted grade of unalloyed medium carbon steel. It is a medium strength steel having good tensile strength and better properties than mild steel. Due to its excellent machinability and mechanical properties, EN-8 is generally used in the production of transmission shafts, gears, bolts, studs, stressed pins, etc. But fatigue failure plays a vital role in the life of such components. Hence, the fatigue strength enhancement becomes indispensable if the life of components made of EN-8 is to be extended.

Bhateja [12] compared the effect of hardness on specimens of three steel grades, namely EN-31, EN-8, and D3 after undergoing heat treatments. The results of the study indicated that the specimens subjected to hardening and tempering are harder and these treatments result in better corrosion resistance than other treatments. It can be noted that less research has been done on EN-8 steel and the effect of hardness after heat treatment has not been studied. Ismail [13] studied the impact of heat treatment on hardness and other properties of medium carbon steel. It was observed that the specimen exhibited better mechanical properties after tempering, thereby reducing brittleness and hardness. Li [14] estimated fatigue life of different medium carbon steels with different surface roughness using a mathematical model and then validated the estimated results by comparing them with experimental results. Senthilkumar [15] investigated the effect of heat treatment such as nitriding, induction hardening, combined nitriding and induction hardening on EN-8 steel. It was found that due to the combined nitriding and induction hardening process chemical changes has occurred which increased microhardness of the surface and microhardness was varying inversely proportional to the depth. Also, this process yielded more favourable hardness values, higher endurance limit and tensile strength when compared to individual processes carried out on the same sample. With an increase in tensile strength and hardness, the fatigue life of the sample also increases.

\section{Experimental setup}

\subsection{Materials and methods}

The material investigated in this study is EN-8 (AISI 1040) steel. Its chemical composition and mechanical properties are summarized in Table 1 and 2.

Table 1 Chemical composition of EN-8 (AISI 1040) steel

\begin{tabular}{lcccccccc}
\hline Element & Fe & C & Mn & Si & P & S & Cr & Ni \\
\hline Weight (\%) & 98.26 & 0.44 & 0.82 & 0.26 & 0.16 & 0.03 & 0.01 & 0.01 \\
\hline
\end{tabular}

Table 2 Mechanical properties of EN-8 steel (normalized-condition)

\begin{tabular}{lcccc}
\hline Properties & $\begin{array}{c}\text { Tensile yield strength } \\
(0.2 \% \text { offset })(\mathrm{MPa})\end{array}$ & $\begin{array}{c}\text { Ultimate tensile } \\
\text { strength }(\mathrm{MPa})\end{array}$ & $\begin{array}{c}\% \text { of elongation } \\
\text { (total) }\end{array}$ & $\begin{array}{c}\text { Hardness } \\
\text { (HRC) }\end{array}$ \\
\hline Values & 280 & 550 & 16 & 16 \\
\hline
\end{tabular}


The used specified EN-8 steel was in the form of round bars with a nominal diameter of $14 \mathrm{~mm}$. The selection of samples for each process is summarized in Table 3.

Table 3 Number of samples for each process.

\begin{tabular}{lcccc}
\hline Category of sample & WT & Q\&T & SP & $\begin{array}{c}\text { Combined } \\
\text { Q\& T and SP }\end{array}$ \\
\hline Tensile and hardness test & 3 & 3 & 3 & 3 \\
\hline $\begin{array}{l}\text { Fatigue test } \\
\text { (4 samples per each stress value) }\end{array}$ & 16 & 16 & 16 & 16 \\
\hline
\end{tabular}

The numerals in the table indicate the number of samples that were subjected to each process and type of test. The supplied EN-8 steel rods were machined using a CNC machine tool according to the testing standards for tensile and fatigue testing.

\subsection{Quenching and tempering}

In this experiment, the quenching and tempering process was accomplished in two steps. At the outset, the machined samples were heated up to $870^{\circ} \mathrm{C}$ for 60 minutes, then suddenly cooled by oil. In the next step, the samples were heated up to $220^{\circ} \mathrm{C}$ and then allowed to cool down in the presence of atmospheric air for about 120 minutes. This process improves mechanical properties and reduces brittleness and internal stresses.

\subsection{Shot peening}

The shot peening process generates a compressive residual stress layer on the outer surface of samples. The samples were shot peened on the outer surface with $0.1 \mathrm{~mm}$ high carbon cast steel shot for 100 seconds under the pressure of 0.6 MPa. It enhances fatigue life of the metal significantly.

\subsection{Combined Q\&T and SP process}

This combined Q\&T and SP process is intended to produce a combined effect in the metal with respect to the desired purpose. This process started with Q\&T and was followed by SP since Q\&T affects the properties of a component while SP affects only the surface.

\subsection{Hardness and tensile test}

The samples were prepared as per the requirement of the testing standards, i.e, ASTM: E18 (hardness test) and IS: 1828/BS: 1610 (tensile test) and the experiment was conducted on Mech.CS.RAS and UTM-40 Ton machines to determine hardness and tensile strength in each category.

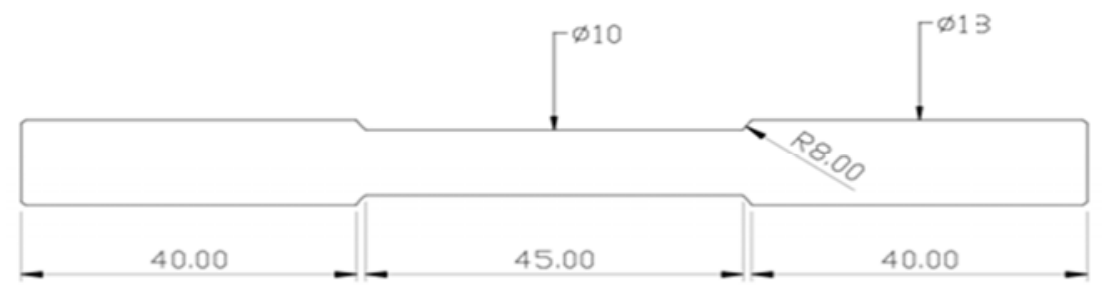

Fig. 3 Tensile test sample

The values of hardness and tensile strength determined for each process are listed in Table 4. 
Heat Treatment and Shot Peening Processes

Table 4 Experimental values of tensile and hardness test

\begin{tabular}{|c|c|c|c|c|c|}
\hline Sample No & Sample type & $\begin{array}{c}\text { Tensile yield stress } \\
(0.2 \% \text { offset }) \\
(\mathrm{MPa}) \\
\end{array}$ & $\begin{array}{c}\text { Tensile } \\
\text { ultimate } \\
\text { stress (MPa) } \\
\end{array}$ & $\begin{array}{c}\text { \% of } \\
\text { elongation } \\
\text { (total) } \\
\end{array}$ & $\begin{array}{c}\text { Rockwell } \\
\text { hardness } \\
\text { (HRC) } \\
\end{array}$ \\
\hline \multirow{3}{*}{1} & \multirow{3}{*}{ Standard samples } & 280 & 560 & 17 & 16 \\
\hline & & 300 & 570 & 16 & 17 \\
\hline & & 290 & 540 & 18 & 15 \\
\hline \multirow{3}{*}{2} & \multirow{3}{*}{ Q\&T samples } & 354 & 624 & 12 & 23 \\
\hline & & 364 & 634 & 11 & 25 \\
\hline & & 375 & 645 & 10 & 28 \\
\hline \multirow{3}{*}{3} & \multirow{3}{*}{$\begin{array}{l}\text { Shot peening } \\
\text { samples }\end{array}$} & 345 & 655 & 13 & 22 \\
\hline & & 334 & 644 & 14 & 21 \\
\hline & & 322 & 621 & 15 & 20 \\
\hline \multirow{3}{*}{4} & \multirow{3}{*}{$\begin{array}{l}\text { Combined Q\&T } \\
\text { and SP samples }\end{array}$} & 390 & 660 & 10 & 28 \\
\hline & & 420 & 690 & 8 & 32 \\
\hline & & 410 & 680 & 9 & 30 \\
\hline
\end{tabular}

\subsection{Rotary bending type fatigue test}

The test samples were prepared as per the testing standards (IS: 5075-1969) and the test was conducted on a MFT-8-D rotary bending type testing machine at a speed of $4500 \mathrm{rpm}$ for predicting the endurance limit of different types of samples.

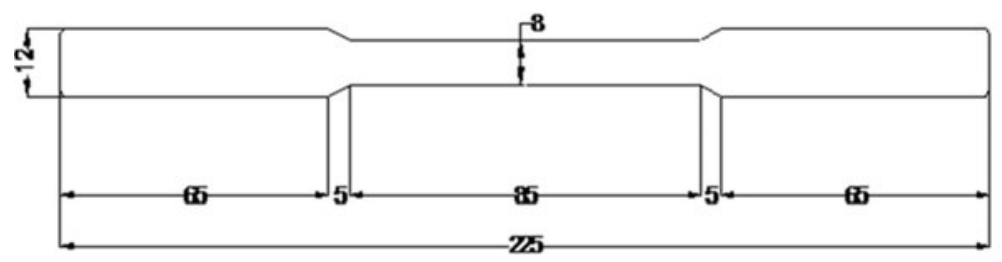

Fig. 4 Fatigue test sample dimensions

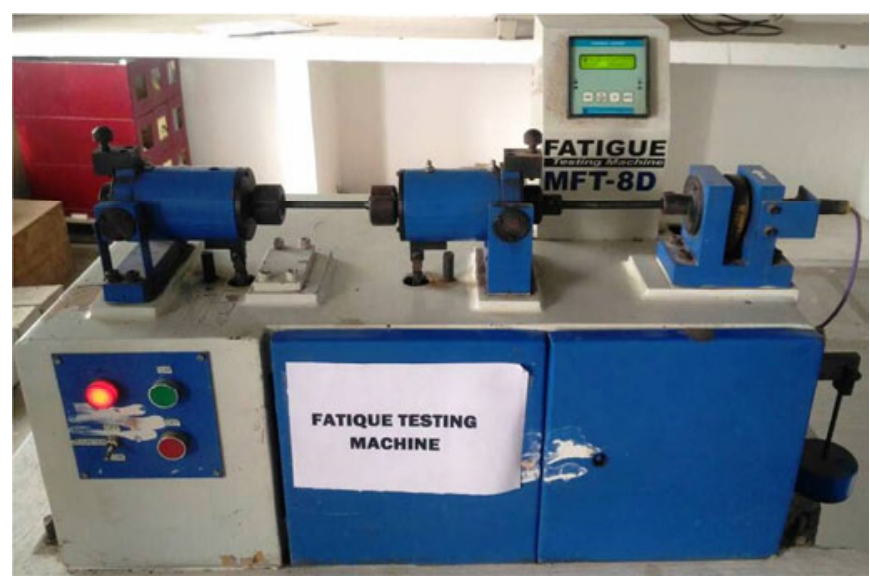

Fig. 5 Fatigue testing machine

In general, the endurance limit value of the EN-8 steel varies from half of the value of the tensile strength to the maximum value of $290 \mathrm{MPa}$. Hence, the fatigue test was conducted on WT, Q\&T, SP, and combined Q\&T and SP samples with the applied stress greater than $290 \mathrm{MPa}$.

The fatigue test values, i.e. the bending stress and the corresponding maximum numbers of cycles enduring before fracture are summarized in Table 5. 
Table 5 Experimental values of rotary bending fatigue test

\begin{tabular}{|c|c|c|c|c|}
\hline Sample No & Sample type & $\begin{array}{c}\text { Bending stress } \\
(\mathrm{MPa})\end{array}$ & Sample number & $\begin{array}{c}\text { Average number } \\
\text { of cycles }\end{array}$ \\
\hline \multirow{4}{*}{1} & \multirow{4}{*}{ Standard samples } & 397.90 & $1,2,3,4$ & $7.26 \mathrm{E}+05$ \\
\hline & & 348.20 & $1,2,3,4$ & $9.90 \mathrm{E}+05$ \\
\hline & & 298.42 & $1,2,3,4$ & $1.19 \mathrm{E}+06$ \\
\hline & & 293.45 & $1,2,3,4$ & $1.32 \mathrm{E}+06$ \\
\hline \multirow{4}{*}{2} & \multirow{4}{*}{ Q\&T samples } & 397.90 & $1,2,3,4$ & $1.01 \mathrm{E}+06$ \\
\hline & & 348.20 & $1,2,3,4$ & $1.39 \mathrm{E}+06$ \\
\hline & & 298.42 & $1,2,3,4$ & $1.66 \mathrm{E}+06$ \\
\hline & & 293.45 & $1,2,3,4$ & $1.85 \mathrm{E}+06$ \\
\hline \multirow{4}{*}{3} & \multirow{4}{*}{$\begin{array}{l}\text { Shot peening } \\
\text { samples }\end{array}$} & 397.90 & $1,2,3,4$ & $8.71 \mathrm{E}+05$ \\
\hline & & 348.20 & $1,2,3,4$ & $1.19 \mathrm{E}+06$ \\
\hline & & 298.42 & $1,2,3,4$ & $1.43 \mathrm{E}+06$ \\
\hline & & 293.45 & $1,2,3,4$ & $1.58 \mathrm{E}+06$ \\
\hline \multirow{4}{*}{4} & \multirow{4}{*}{$\begin{array}{l}\text { Combined Q\&T } \\
\text { and SP samples }\end{array}$} & 397.90 & $1,2,3,4$ & $1.27 \mathrm{E}+06$ \\
\hline & & 348.20 & $1,2,3,4$ & $1.73 \mathrm{E}+06$ \\
\hline & & 298.42 & $1,2,3,4$ & $2.08 \mathrm{E}+06$ \\
\hline & & 293.45 & $1,2,3,4$ & $2.31 \mathrm{E}+06$ \\
\hline
\end{tabular}

\subsection{Photographic images of treated and fatigue failure samples}

The figures depict fatigue tested samples that underwent various processes and their fractured surfaces. Figure 6 shows samples before and after the Q\&T was carried out. Figure 7 shows the fatigue failure of different processed samples (after fatigue failure). Figures 8 to 11 illustrate the fracture and surface discontinuity occurring in different processes.

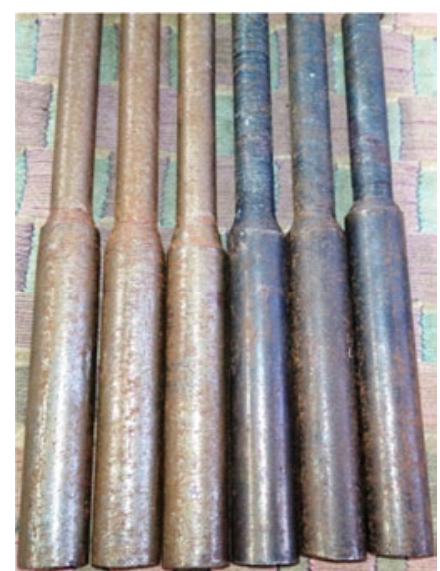

Fig. 6 Samples before and after Q\&T

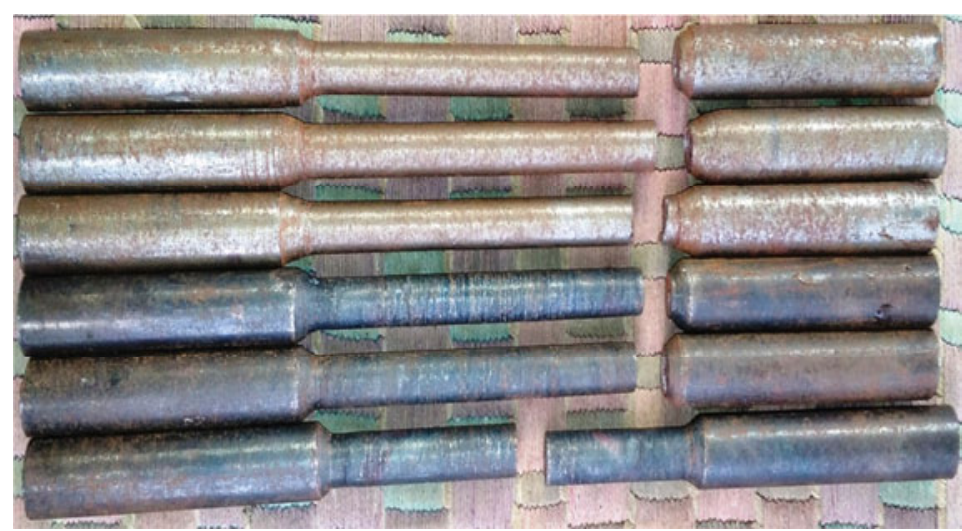

Fig. 7 Samples after fatigue testing and SP

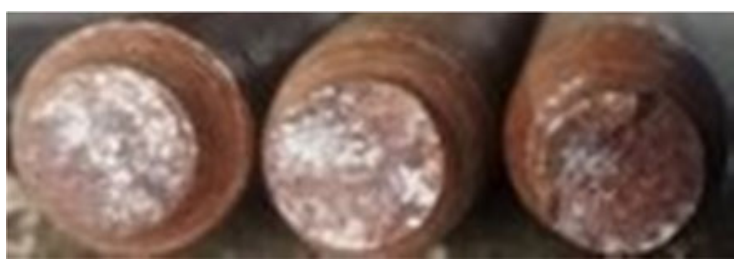

Fig. 8 Fractured surface of WT samples

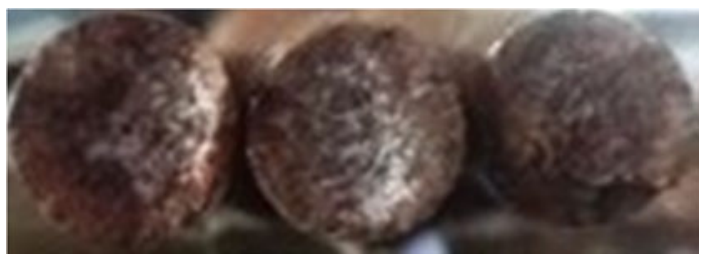

Fig. 9 Fractured surface of Q\&T samples 


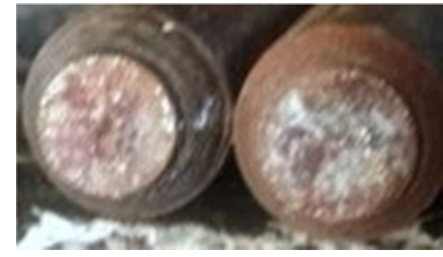

Fig. 10 Fractured surface of SP samples

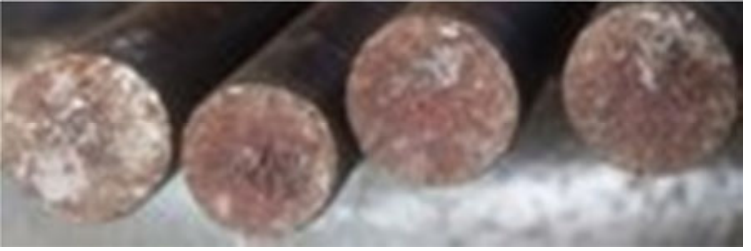

Fig. 11 Fractured surface of combined Q\&T and SP samples

\section{Experimental results and discussion}

\subsection{Tensile and hardness response of all types of samples}

It is clear from the values given in Table 4 and from Figures 12 and 13, that the yield and the ultimate stress and hardness of the combined Q\&T and SP samples are greater than those of other types of samples. The only exception is the percentage of elongation as it is lower than in the case of other types of samples. This property of reduced ductility increases the fatigue strength of the desired material.

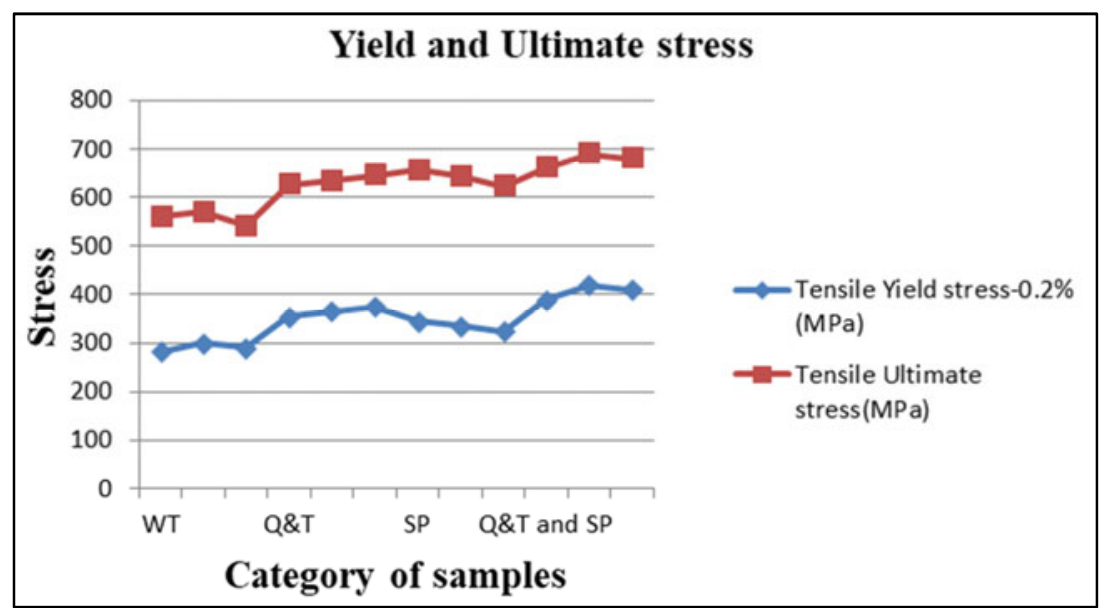

Fig. 12 Yield and ultimate stress

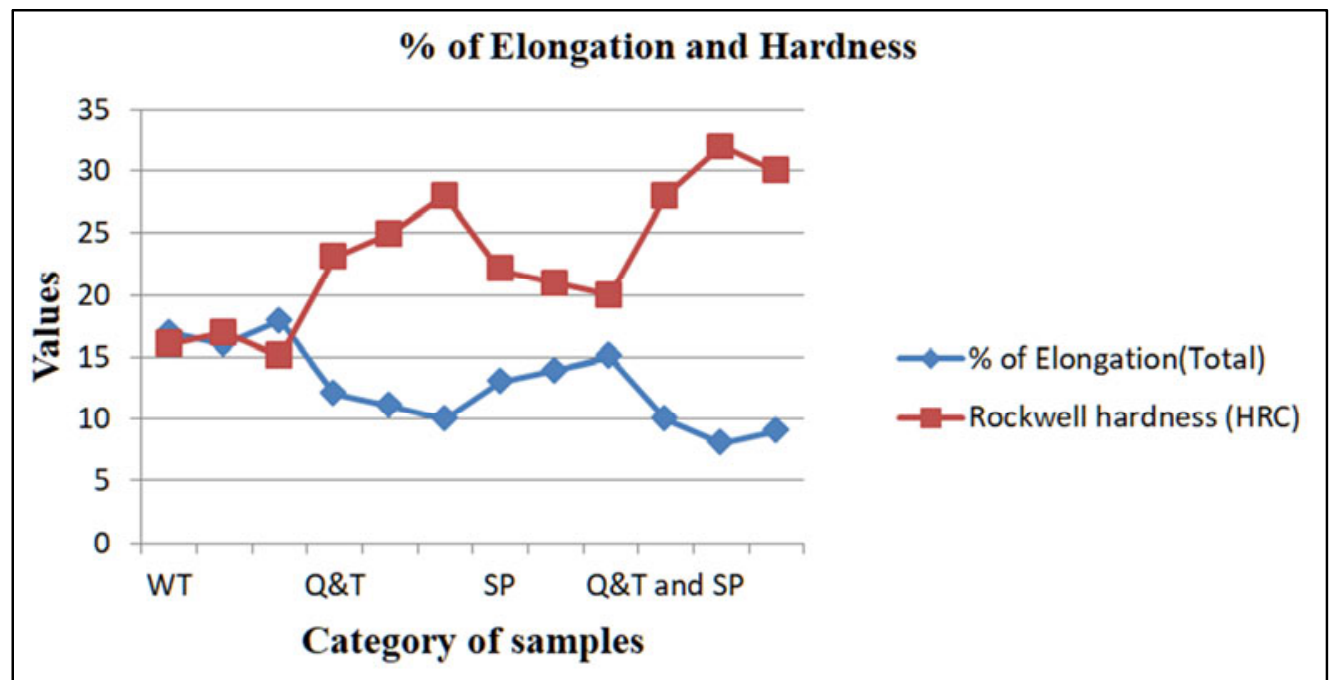

Fig. 13 Percentage of elongation and hardness 


\subsection{Fatigue behaviour of all types of samples}

From Table 5 and Figure 14 it can be seen that with respect to fatigue life, the Q\&T and SP samples exhibit superior properties in comparison to standard samples. When considering Q\&T and SP individually, the Q\&T samples are superior. The combined Q\&T and SP samples have more favourable fatigue strength values than other category samples. The results are in conformity with the fact that fatigue strength increases when the stress value decreases.

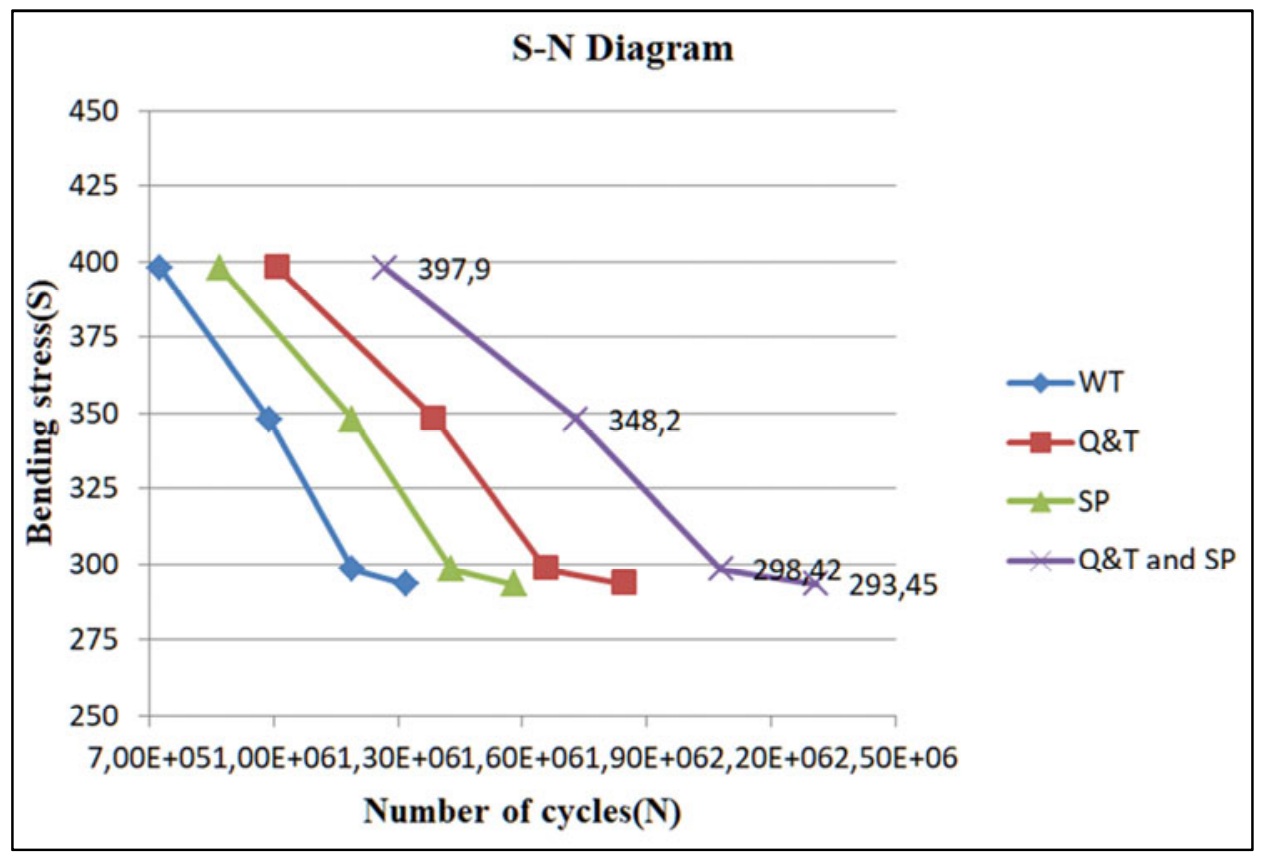

Stress ratio $(\mathrm{R}=-1)$, completely reversed

Fig. 14 S-N diagram of rotary bending fatigue test

\subsection{Statistical analysis}

Analysis of variance was performed on the different processed samples with the average number of cycles. It is inferred that the process has a statistically significant effect on the average number of cycles $[\mathrm{F}=3.635 @ \mathrm{p}<0.05]$. The inferences are drawn from the fact that the effects of the processes are different, which is evident from the mean values of the processes (Table 6) that range from 1847500 to 1056500 . The combined Q\&T \& SP process has the highest value (1847500) and the case without any treatment has the lowest value (1056500).

The fatigue strength of the samples linearly varies with the average number of cycles, i.e. the fatigue strength increases with an increase in the average number of cycles. It is evident from the result that the combined Q\&T and SP processed samples have higher fatigue strength due to the higher average number of cycles than the samples that were subjected to the WT, Q\&T and SP processes. 
EN-8 Steel (080M40/AISI 1040) Subjected to

Heat Treatment and Shot Peening Processes

Table 6 ANOVA results with average number of cycles

\begin{tabular}{|c|c|c|c|c|c|c|c|c|}
\hline \multicolumn{9}{|c|}{ Descriptive } \\
\hline & \multirow{2}{*}{$\mathbf{N}$} & Mean & Std. deviation & Std. error & \multicolumn{2}{|c|}{$\begin{array}{r}\text { A5\% confidence interval for } \\
\text { mean }\end{array}$} & \multirow{2}{*}{ Minimum } & \multirow{2}{*}{ Maximum } \\
\cline { 5 - 8 } & & & & & Lower bound & Upper bound & & \\
\hline WT & $\mathbf{4}$ & 1056500.0000 & 258783.69346 & 129391.84673 & 644717.3954 & 1468282.6046 & 726000.00 & $1.32 \mathrm{E}+6$ \\
\hline Q \& T & $\mathbf{4}$ & 1477500.0000 & 364360.16980 & 182180.08490 & 897721.6619 & 2057278.3381 & $1.01 \mathrm{E}+6$ & $1.85 \mathrm{E}+6$ \\
\hline SP & $\mathbf{4}$ & 1267750.0000 & 309451.53094 & 154725.76547 & 775343.5594 & 1760156.4406 & 871000.00 & $1.58 \mathrm{E}+6$ \\
\hline $\begin{array}{c}\text { Combined } \\
\text { Q\&T\& SP }\end{array}$ & $\mathbf{4}$ & 1847500.0000 & 452870.47449 & 226435.23725 & 1126882.0158 & 2568117.9842 & $1.27 \mathrm{E}+6$ & $2.31 \mathrm{E}+6$ \\
\hline Total & $\mathbf{1 6}$ & 1412312.5000 & 437133.95639 & 109283.48910 & 1179380.2568 & 1645244.7432 & 726000.00 & $2.31 \mathrm{E}+6$ \\
\hline
\end{tabular}

Data presented in Table 7 show that the interaction effect of the process indicates that the significant difference between the combined Q\&T and SP process and WT is greater than the difference between the combined Q\&T and SP process and the processes of Q\&T and SP.

Table7 Results of Tukey HSD test

\begin{tabular}{|c|c|c|c|c|c|c|}
\hline \multicolumn{7}{|c|}{ Multiple comparisons } \\
\hline \multicolumn{7}{|c|}{ Dependent variable: Average no.of cycles } \\
\hline \multicolumn{7}{|c|}{ Tukey HSD } \\
\hline \multirow{2}{*}{ (I)Sample types } & \multirow{2}{*}{ (J)Sample types } & \multirow{2}{*}{$\begin{array}{c}\text { Mean difference } \\
(\mathrm{I}-\mathrm{J})\end{array}$} & \multirow{2}{*}{ Std. error } & \multirow{2}{*}{ Sig. } & \multicolumn{2}{|c|}{$95 \%$ confidence interval } \\
\hline & & & & & Lower bound & Upper bound \\
\hline \multirow{3}{*}{ WT } & Q \& T & -421000.00000 & 250144.77058 & .373 & -1163655.0899 & 321655.0899 \\
\hline & SP & -211250.00000 & 250144.77058 & .832 & -953905.0899 & 531405.0899 \\
\hline & Combined Q \&T \& SP & $-791000.00000^{*}$ & 250144.77058 & .036 & -1533655.0899 & -48344.9101 \\
\hline \multirow{3}{*}{ Q \& T } & WT & 421000.00000 & 250144.77058 & .373 & -321655.0899 & 1163655.0899 \\
\hline & SP & 209750.00000 & 250144.77058 & .835 & -532905.0899 & 952405.0899 \\
\hline & Combined Q \& T \& SP & -370000.00000 & 250144.77058 & .479 & -1112655.0899 & 372655.0899 \\
\hline \multirow{3}{*}{ SP } & WT & 211250.00000 & 250144.77058 & .832 & -531405.0899 & 953905.0899 \\
\hline & $\mathrm{Q} \& \mathrm{~T}$ & -209750.00000 & 250144.77058 & .835 & -952405.0899 & 532905.0899 \\
\hline & Combined Q \& T \& SP & -579750.00000 & 250144.77058 & .148 & -1322405.0899 & 162905.0899 \\
\hline \multirow{3}{*}{$\begin{array}{l}\text { Combined } \\
\text { Q \&T \& SP }\end{array}$} & WT & $791000.00000^{*}$ & 250144.77058 & .036 & 48344.9101 & 1533655.0899 \\
\hline & Q \& T & 370000.00000 & 250144.77058 & .479 & -372655.0899 & 1112655.0899 \\
\hline & SP & 579750.00000 & 250144.77058 & .148 & -162905.0899 & 1322405.0899 \\
\hline
\end{tabular}

The result of the Tukey HSD test (Table 8) indicates that there is no significant difference between two subsets as the values of subset 1 appear in the values of subset 2 .

Table 8 Tukey HSD test results for average number of cycles

\begin{tabular}{|c|c|c|c|}
\hline \multicolumn{4}{|c|}{ Average no.of cycles } \\
\hline \multicolumn{4}{|c|}{ Tukey HSD $^{\mathrm{a}}$} \\
\hline \multirow{2}{*}{ Sample types } & \multirow{2}{*}{$\mathbf{N}$} & \multicolumn{2}{|c|}{ Subset for alpha $=0.05$} \\
\hline & & 1 & 2 \\
\hline WT & 4 & 1056500.0000 & \\
\hline SP & 4 & 1267750.0000 & 1267750.0000 \\
\hline Q \& T & 4 & 1477500.0000 & 1477500.0000 \\
\hline Combined Q \&T \& SP & 4 & & 1847500.0000 \\
\hline Sig. & & .373 & .148 \\
\hline \multicolumn{4}{|c|}{ Means for groups in homogeneous subsets are displayed. } \\
\hline \multicolumn{4}{|c|}{ a. uses harmonic mean sample size $=4.000$. } \\
\hline
\end{tabular}


The mean plot of the average number of cycles of the combined Q\&T and SP process is greater than that of Q\&T, followed by SP and WT.

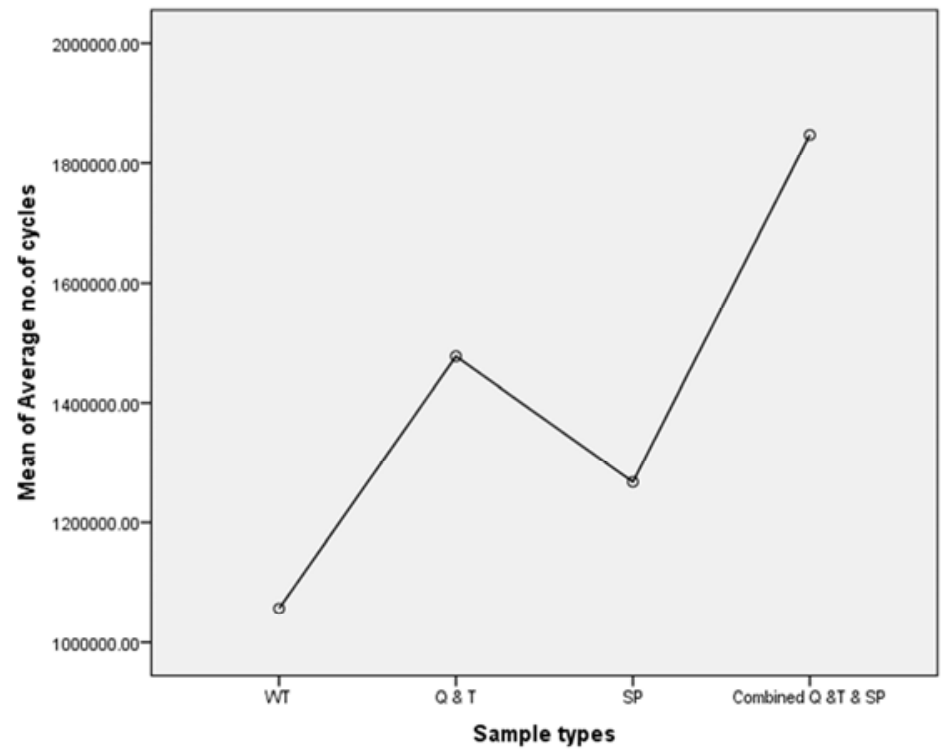

Fig. 15 Mean plot of average number of cycles

\section{Conclusions}

The fatigue behaviour of EN-8 steel is investigated experimentally and the responses of different processes are validated by using the one-way ANOVA.

- The combined Q\&T and SP process increases yield stress (420 MPa), ultimate stress (690MPa) and Rockwell hardness (32HRC) compared to other processes.

- The fact that low ductility of the material increases fatigue strength is supported by the readings i.e the average percentage of elongation for the combined Q\&T and SP sample is $9 \%$.

- The Q\&T and shot peening processes considerably improve fatigue life when applied individually on samples that underwent no treatment.

- For the same stress value of $397.90 \mathrm{MPa}$, the Q\&T process yields the fatigue life of 1.01E6, whereas shot peening yields the fatigue life of 8.71E5. This is less than in the case of Q\&T, and the reason is that Q\&T is done on the entire specimen, while SP is done on the surface only.

- Fatigue life improvement as a result of the Q\&T process is $1.39 \mathrm{E} 5$ greater than in the case of shot peening.

- From the findings and results, the combined Q\&T and SP process results in a significantly longer fatigue life and a greater average number of cycles.

- For the same stress value of $397.90 \mathrm{MPa}$, the combined Q\&T and SP process yields the fatigue life of 1.27E6, which is greater than in the case of Q\&T and shot peening processes.

- Fatigue life improvement as a result of the combined Q\&T and SP process is 5.44E5 greater than in the case of non-treated samples (WT). 
- The ANOVA statistical analysis shows, that the treatment has statistically significant effect on the average number of cycles $(\mathrm{F}=3.635 @ \mathrm{p}<0.05)$.

- Therefore, to improve the fatigue life of EN-8, the use of the combined Q\&T and SP process is highly recommended.

\section{REFERENCES}

[1] Pandey, R.K.; Deshmukh, M .N. Shot peening and its impact on Fatigue life of engineering components, International conference on shot peening and blast cleaning, Department of Applied Mechanics, Indian Institute of Technology, Delhi, India 2001, 1, 1-19.

[2] Kubit, A.; Bucior, M.; Zielecki,W.; Stachowicz, F. The impact of heat treatment and shot peening on the fatigue strength of 51CrV4 steel, ScienceDirect Procedia, 21st European Conference on Fracture, Structural Integrity 2016, June 20-24. https://doi.org/10.1016/j.prostr.2016.06.415

[3] Haradaa,Y.;Tanakaa, S.; Itohb, M.; Nakatania, M. Effect of microshot peening on fatigue life of spring steel SUP9, ScienceDirect Procedia Engineering, 11th International Conference on Technology of Plasticity, ICTP 2014, 81, 1493-1498. https://doi.org/10.1016/j.proeng.2014.10.179

[4] Vielma, A. T.; Llaneza,V.; Belzunce, F. J. Shot peening intensity optimization to increase the fatigue life of a quenched and tempered structural steel. Procedia Engineering 2014, 74, 273-278. https://doi.org/10.1016/j.proeng.2014.06.261

[5] Tekeli, S. Enhancement of Fatigue strength SAE9245 Steel by shot peening, Material letters 2002, 57(3), 604-608. https://doi.org/10.1016/s0167-577x(02)00838-8

[6] Tanwer, A. K. Effect of Various Heat Treatment Processes on Mechanical Properties of Mild Steel and Stainless Steel, American International Journal of Research in Science, Technology, Engineering \& Mathematics 2014, 8(1), 57-61.

[7] Korade, D. N.; Dandge,V.M.; Ramana, K.V.; Jagtap,K.R. Effect of Heat Treatments on Fatigue Failure and Fracture Toughness of Various Tool Steels - A Review, International Journal of Current Engineering and Technology 2016, (4), 296- 302. https://doi.org/10.14741/ijcet/22774106/spl.4.2016.61

[8] Nacy, S.M. Effect of heat treatment on fatigue behavior of (A193-51T-B7) alloy steel, Proceedings of World Congress on Engineering 2007, 2.

[9] Schino, A.D.; Corradi,M. Quenching and Tempering effect on a steel for forging with $\mathrm{Cr}$ and $\mathrm{Mo}$ addition, Metalurgija 2018, 57 (4), 307-309.

[10] Rawdon, H.S.; Epstein, S. Structure of Martensitic carbon steels and changes in the microstructure which occur upon tempering, Scientific Papers for the Bureau of Standards 1922, 18, 373-409. https://doi.org/10.6028/nbsscipaper.115

[11] Senthil Kumar, M.; Ragunathan, S.; Suresh, M.; Srinivashan,V.R. Study of surface heat treatment and its effects on fatigue behavior of steel - A Review. Advances in natural and applied sciences 2016, 10(7), 309-318.

[12] Ashish Bhateja,; Aditya Varma,; Ashish Kashyap.; Bhupinder Singh. Study the Effect on the Hardness of three Sample Grades of Tool Steel i.e. EN-31, EN-8, and D3 after Heat Treatment Processes Such As Annealing, Normalizing, and Hardening \& Tempering, The International Journal of Engineering and Science (IJES) 2012, 1(2), 253-259.

[13] Ismail, N.M.; Khatif, N .A. A.; Kecik, M. A. K. A.; Shaharudin, M. A. H. The effect of heat treatment on the hardness and impact properties of medium carbon steel, IOP Conf. Series, Materials Science and Engineering, 2016, 114(1), https://doi.org/10.1088/1757-899x/114/1/012108

[14] ChangyouLi,; Weibing Dai,; Fei Duan,; Yimin Zhang,; David He. Fatigue Life Estimation of MediumCarbon Steel with Different Surface Roughness, Applied Sciences 2017, 7 (4), 1-11. https://doi.org/10.20944/preprints201703.0187.v1

[15] Senthil Kumar,M.; Ragunathan,S.; Srinivasan,V.R. Effect of heat treatment on the fatigue behavior of En8 steel, ARPN Journal of Engineering and Applied Sciences 2016, 11(2), 1326-1339. 

EN-8 Steel (080M40/AISI 1040) Subjected to Heat Treatment and Shot Peening Processes

Submitted: $\quad 12.11 .2018$

Accepted: $\quad 03.4 .2019$
Chinnadurai Prabhu

Mahendra College of Engineering,

Department of Mechanical Engineering, Salem District, Tamilnadu, India

Murugesan Jayaraman

Velalar College of Engineering and

Technology, Department of Mechanical Engineering, Erode District,

Tamilnadu India

Mani Rajnikanth

Sree Venkateshwara College of

Engineering, Department of Mechanical

Engineering, Bengaluru, India 